University of South Carolina

Scholar Commons

1987

\title{
A Mathematical Model for the Initial Corrosion Rate of a Porous Layer on a Rotating Disk Electrode
}

\author{
William E. Ryan \\ Texas A \& M University - College Station \\ Ralph E. White \\ University of South Carolina - Columbia, white@cec.sc.edu
}

S. L. Kelly

Follow this and additional works at: https://scholarcommons.sc.edu/eche_facpub

Part of the Chemical Engineering Commons

\section{Publication Info}

Journal of the Electrochemical Society, 1987, pages 2154-2159.

(c) The Electrochemical Society, Inc. 1987. All rights reserved. Except as provided under U.S. copyright law, this work may not be reproduced, resold, distributed, or modified without the express permission of The Electrochemical Society (ECS). The archival version of this work was published in the Journal of the Electrochemical Society.

http://www.electrochem.org/

DOI: $10.1149 / 1.2100842$

http://dx.doi.org/10.1149/1.2100842

This Article is brought to you by the Chemical Engineering, Department of at Scholar Commons. It has been accepted for inclusion in Faculty Publications by an authorized administrator of Scholar Commons. For more information, please contact digres@mailbox.sc.edu. 


\title{
A Mathematical Model for the Initial Corrosion Rate of a Porous Layer on a Rotating Disk Electrode
}

\author{
William E. Ryan and R. E. White* \\ Department of Chemical Engineering, Texas A\&M University, College Station, Texas 77843
}

S. L. Kelly*

The Dow Chemical Company, Texas Applied Science and Technology Laboratories, Freeport, Texas 77541

\section{ABSTRACT}

A mathematical model is presented for the initial corrosion rate of a porous layer on a rotating disk electrode. The model is used to predict the corrosion potential and corrosion current density for a porous electrode made of pure iron in aerated caustic solutions. The dependence of these predictions on some of the properties of the porous layer is presented. It is shown that the corrosion rate depends significantly on the specific surface area of the porous electrode.

Conducting porous layers on electrodes are often used as electrocatalysts or supports for electrocatalysts. The corrosion of these layers can lead to the loss of the electrocatalyst; to study this, a steady-state mathematical model for the initial corrosion rate of a conducting porous layer on a rotating disk electrode (RDE) has been developed and is reported here.

Previous porous electrode models have been presented and are reviewed by Newman and Tiedemann (1). Simplifying assumptions have been used in the development of some of the models (2-4) to obtain analytical expressions. For example, Ksenzhek (2) solved analytically the equation for an infinitely thick electrode model in which he assumed that the ohmic potential drops in both the solution and matrix phases were negligible. Also, Gurevich and Bagotzky (3) developed a complicated analytic solution for porous diffusion electrodes by using simplifying assumptions. Van Zee and White (4) developed a one-dimensional analytic expression for flow past a porous electrode by including an external masstransfer coefficient in the governing equation.

Grens and Tobias (5) and Grens (6) examined the consequences of the several common simplifying assumptions used in modeling porous electrodes and found many to be severely restrictive. Some of those that were considered to be poor are the assumptions of infinite electrode thickness, uniform concentration or conductivity of pore filling electrolyte, and negligible potential gradient in the pores. [Austin (7), on the other hand, reasserted the value of simplifying assumptions as useful in obtaining good approximations for limited situations. However, he did uphold that theoretical treatments that neglect internal mass transfer are in error.] The model presented below does not have these limiting assumptions. However, it does have others such as the solid matrix of the porous layer is assumed to be isopotential (i.e., the porous layer is assumed to be infinitely conductive), as discussed further below.

A large body of literature exists which deals with theoretical descriptions of corrosion in electrochemical systems, although none deal specifically with the analysis of conducting porous layers, as was pointed out recently by Chang and Prentice (8). In their case, the corrosion of zinc was of concern and the ability to predict the local $p \mathrm{H}$ of the solution prompted their study. The model presented below is more comprehensive than theirs since they assumed that a single pore model could be used to describe a porous layer.

Several models have been proposed for the determination of localized corrosion rates for a smooth RDE. Vahdat and Newman (9) and Law and Newman $(10,11)$ suggest a mechanism for iron passivation and demonstrate how the Butler-Volmer kinetic rate equation can be used to account for this phenomena on the RDE surface. However, their approach neglects the effect of ionic migration of charged species.

*Electrochemical Society Active Member.

\section{Model Development}

The model is developed by presenting a summary of the assumptions, a description of the modeled regions, the governing equations and assumptions for each region, and finally the boundary conditions.

Summary of assumptions.-The major assumptions used in the development of the model are: one spatial coordinate $(y)$, dilute solution theory, steady-state, no homogeneous chemical reactions, isopotential matrix phase (solid phase) in the porous layer, smooth porous electrode/electrolyte interface, no convection in the porous layer, constant porosity and thickness of the porous layer, and no potential drop between the reference electrode lead and the solution at the luggin tip.

Description of modeled regions.-A schematic of a typical experimental apparatus for a RDE with a thin porous layer is shown in Fig. 1. As shown there, a Luggin capillary is placed as close as possible to the center of the RDE. This allows the reference electrode, a saturated calomel electrode (SCE), to detect the solution potential near the working electrode at a known distance $\left(y=y_{\mathrm{RE}}\right)$ from the electrode surface. Two regions are included in the model, as shown in Fig. 2: the diffusion layer and the porous electrode layer. The model equations are different in each region, as explained below.

Governing equations and assumptions-diffusion layer.-The flux of species $i$ in the solution in the diffusion layer is due to migration, diffusion, and convection

$$
\mathbf{N}_{\mathrm{i}}=-z_{\mathrm{i}} u_{\mathrm{i}} \mathbf{F} c_{\mathrm{i}} \nabla \Phi-D_{1} \nabla c_{\mathrm{i}}+v c_{\mathrm{i}}
$$

where the ionic mobility, $u_{i}$, is assumed to be given by the Nernst-Einstein equation

$$
u_{\mathrm{i}}=\frac{D_{\mathrm{i}}}{R T}
$$

The concentration of each of $n$ species is governed by the material balance equation

$$
\frac{\partial c_{\mathrm{t}}}{\partial t}=-\nabla \cdot \mathbf{N}_{\mathrm{i}}+R_{\mathrm{i}}
$$

and the condition of electroneutrality

$$
\sum_{i} z_{i} c_{i}=0
$$

is used as the governing equation for $\Phi$.

Several assumptions are used to simplify the material balance expression. First, the system is taken to be at steady state with no homogeneous chemical reactions in the diffusion layer. Thus, $\partial c_{\mathrm{i}} / \partial t=0$ and $R_{\mathrm{i}}=0$ in Eq. [3]. Next, it is assumed that transport occurs only in the axial direction (i.e., $y$-direction), and that the velocity component in the axial direction depends. only on the distance from the porous electrode surface 


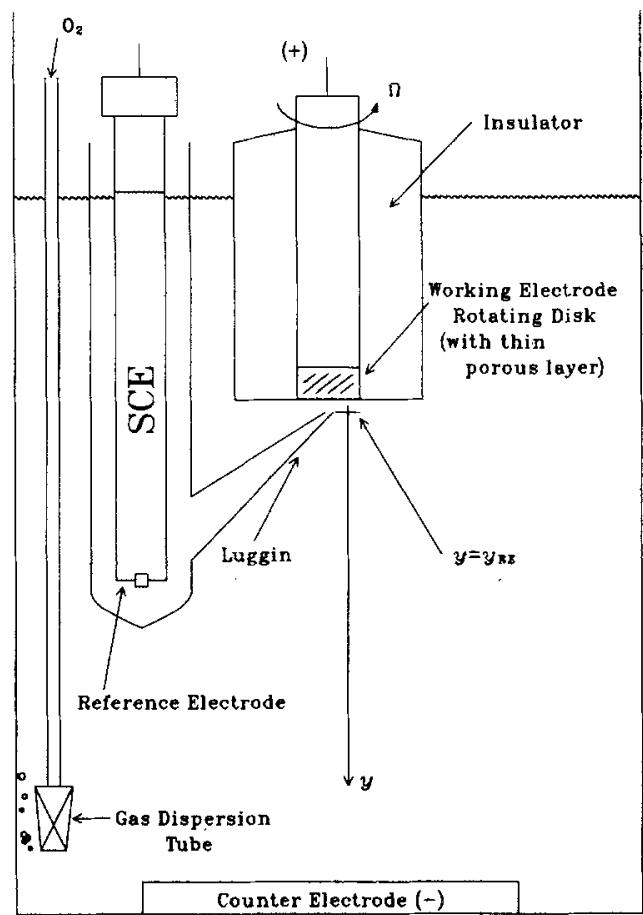

Fig. 1. Schematic of rotating disk electrode experimental cell

$$
v_{y}=-a^{\prime} \Omega \sqrt{\frac{\Omega}{v}}\left(y-y_{\mathrm{PE}}\right)^{2}
$$

for $y>y_{\mathrm{PE}}$, and

$$
v_{y}=0
$$

for $y \leq y_{\mathrm{PE}}$, according to the no slip condition (at $y=y_{\mathrm{PF}}$ ) and the assumption that there is no convection within the porous layer. Also, it seems reasonable to treat the porous region as a smooth surface for cases where the surface area is mostly internal. This may not be a good assumption for rough surfaces. Combining Eq. [1], [2], [3], and [5] yields the governing equation for species $i$ within the diffusion layer

$$
\begin{aligned}
& -\frac{z_{\mathrm{i}} D_{\mathrm{i}} \mathbf{F}}{R T}\left(c_{1} \frac{d^{2} \Phi}{d y^{2}}+\frac{d c_{\mathrm{i}}}{d y} \frac{d \Phi}{d y}\right) \\
& \quad+D_{\mathrm{i}} \frac{d^{2} c_{\mathrm{i}}}{d y^{2}}+a^{\prime} \Omega \sqrt{\frac{\Omega}{v}}\left(y-\delta_{\mathrm{PE}}\right)^{2} \frac{d c_{\mathrm{i}}}{d y}=0
\end{aligned}
$$

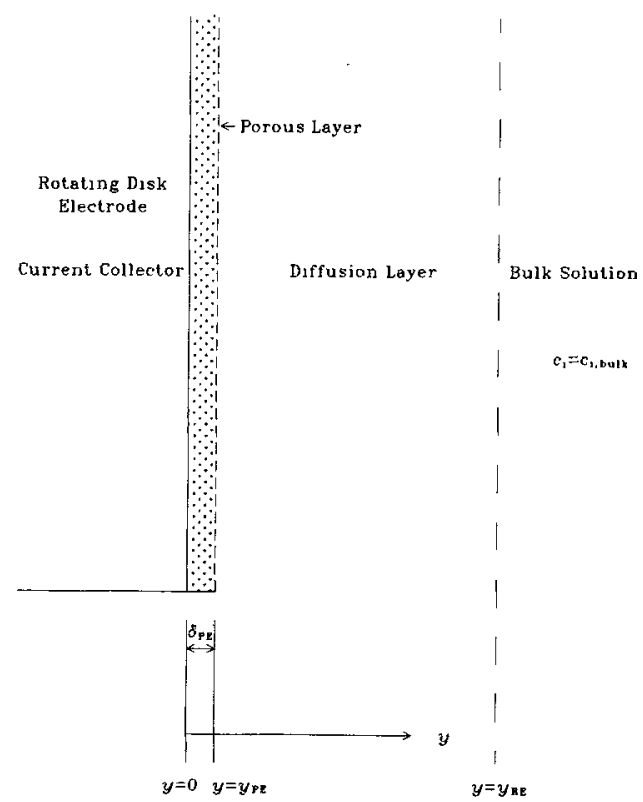

Fig. 2. Schematic of a porous layer on a rotating disk electrode
Governing equations and assumptions-porous electrode layer.-In the porous electrode region, macroscopic parameters are used to describe the layer without regard to the actual geometric detail of the pore structure $(1,12,13)$. Two parameters are useful in defining average quantities for characterizing transport phenomena in the porous layer: porosity, $\epsilon$, and the MacMullin number for the porous electrode layer (14), $N_{\text {M.PE }}$

$$
N_{\mathrm{M}, \mathrm{PE}}=\tau / \epsilon
$$

where $\tau$ represents the tortuosity of the porous layer.

To account for the nonhomogeneous structure of the porous matrix, averaging is applied within a volume element throughout the porous layer. The concentration per unit volume of electrolyte of a species $i$ is given by $c_{i}$. The superficial concentration, $\epsilon c_{1}$, represents the average concentration per total unit volume including the solid matrix and the electrolyte occupying the spaces within the matrix. Electrochemical reactions are described in terms of individual reaction current densities, $j_{j}$, in amperes per square centimeter of electroactive area. The value of $j_{j}$ is a function of position within the porous layer. The electrochemical reaction rate can be related to the volume of the porous layer by multiplying $j_{\mathrm{j}}$ by the electroactive specific surface area $a: a j_{j}$. Integration of $a j$, over the thickness of the porous layer yields the average superficial current density for the porous layer $i_{j}$ (i.e., the current for reaction $j$ divided by the projected geometric surface area of the porous electrode layer).

Within the porous layer, the material balance equation is formulated in terms of average quantities and includes a reaction rate term which accounts for local electrochemical reactions, $R_{i}^{\prime}$

$$
\frac{\partial\left(\epsilon c_{\mathrm{i}}\right)}{\partial t}=-\nabla \cdot \mathbf{N}_{\mathrm{i}}+R_{1}+R_{\mathrm{i}}^{t_{1}}
$$

The assumptions of steady state with no homogenous reactions as stated earlier are still maintained so that $\partial c_{i} / \partial t$ and $R_{1}$ in Eq. [9] are equal to zero. The porosity, MacMullin number, and porous layer thickness are also assumed to be constant; consequently, $\partial \epsilon / \partial t=0$. With the assumption that there is no convective flow within the porous layer, the flux of species $i$ within the porous layer is

$$
\mathbf{N}_{\mathrm{i}}=-\frac{z_{\mathrm{i}} D_{\mathrm{i}, \mathrm{e}} \mathbf{F}}{R T} c_{1} \nabla \Phi-D_{\mathrm{i}, \mathrm{e}} \nabla c_{\mathrm{i}}
$$

where

$$
D_{\mathrm{i} . \mathrm{e}}=\frac{D_{1}}{N_{\mathrm{M} . \mathrm{PE}}}
$$

Combining Eq. [10] and [11] with the material balance expression, Eq. [9], subject to the assumptions mentioned above, the governing equation for species $i$ within the porous electrode layer becomes

$$
\begin{aligned}
\frac{z_{\mathrm{i}} D_{\mathrm{i}} \mathbf{F}}{N_{\mathrm{M}, \mathrm{PE}} R T}\left(c_{\mathrm{i}} \frac{d^{2} \Phi}{d y^{2}}\right. & \left.+\frac{d c_{\mathrm{i}}}{d y} \frac{d \Phi}{d y}\right) \\
& +\frac{D_{\mathrm{i}}}{N_{\mathrm{M}, \mathrm{PS}}} \frac{d^{2} c_{\mathrm{i}}}{d y^{2}}+R^{\prime}{ }_{\mathrm{i}}=0
\end{aligned}
$$

The production rate of each species $i$ due to all electrochemical reactions is given by (14)

$$
R^{\prime}{ }_{\mathrm{i}}=-a \sum_{j}^{\mathrm{NR}} \frac{s_{\mathrm{ij}} j_{\mathrm{j}}}{n_{\mathrm{j}} \mathbf{F}}
$$

where $N R$ the total number of electrochemical reactions. The local current density due to electrochemical reaction $j$ (relative to the local electroactive surface area) at each point within the porous layer, $j_{j}$, is assumed to be given by the Butler-Volmer equation (15) 


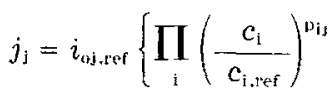

$$
\begin{aligned}
& \exp \left(\frac{\alpha_{\mathrm{ij}} \mathbf{F}}{R T}\left[\left(V-\Phi-U_{\left.\mathrm{J}, \mathrm{r} \mathrm{r}_{\mathrm{l}}\right)}\right)\right)-\prod_{\mathrm{i}}\left(\frac{c_{\mathrm{j}}}{c_{\mathrm{i}, \mathrm{re} \cdot \mathrm{r}}}\right)^{\mathrm{a}_{\mathrm{j} j}}\right. \\
& \left.\exp \left(\frac{-\alpha_{\mathrm{c} j} \mathbf{F}}{R T}\left[\left(V-\Phi-U_{\mathrm{j}, \mathrm{ref}}\right)\right]\right)\right\}
\end{aligned}
$$

where

$$
\begin{gathered}
i_{\text {oj.ref }}=\prod_{i} i_{\text {oj,data }}\left(\frac{c_{\mathrm{l}, \text { ref }}}{c_{\mathrm{i}, \mathrm{d} \text { ata }}}\right)^{\gamma_{\mathrm{ij}}} \\
U_{\mathrm{j}, \text { ret }}=\left[U_{\mathrm{j}}^{\theta}-\frac{R T}{n_{\mathrm{j}} \mathbf{F}} \sum_{\mathrm{j}} s_{\mathrm{i} \mathrm{j}} \ln \left(\frac{c_{\mathrm{i}, \text { ref }}}{\rho_{0}}\right)\right] \\
-\left[U_{\mathrm{RE}}^{\theta}-\frac{R T}{n_{\mathrm{RE}} \mathbf{F}} \sum_{\mathrm{i}} s_{\mathrm{ij}} \ln \left(\frac{c_{\mathrm{i}, \mathrm{RE}}}{\rho_{\mathrm{o}}}\right)\right]
\end{gathered}
$$

or

$$
U_{\mathrm{J} \text {.ref }}=\left[U_{j}^{\theta}-\frac{R T}{n_{j} \mathbf{F}}-\sum_{\mathrm{i}} s_{i,} \ln \left(\frac{c_{\mathrm{i}, \mathrm{ref}}}{\rho_{i j}}\right)\right]-U_{\mathrm{RE}}
$$

It is assumed here that reaction order constants, $p_{\mathrm{ij}}$ and $q_{\mathrm{ij}}$, are related simply to $s_{\mathrm{ij}}$

$$
\begin{array}{llll}
p_{i j}=s_{i j} & q_{i j}=0 & \text { if } & s_{i j}>0 \\
p_{i j}=0 & q_{i j}=-s_{i j} & \text { if } & s_{i j}<0
\end{array}
$$

Also, the concentration dependence of the exchange current density exponents, $\gamma_{i j}$, is assumed to be related to $s_{i j}$ in a consistent way

$$
\gamma_{i j}=p_{i j}-\frac{\alpha_{a j} s_{i j}}{n_{j}}
$$

and

$$
\gamma_{i j}=q_{i j}+\frac{\alpha_{{ }^{j} j} S_{i j}}{n_{j}}
$$

Equation [14] shows that the local current density depends upon the difference between the potential of the matrix phase of the porous electrode, $V$ (assumed here to be a constant), and the potential of the solution just adjacent to the pore surface, $\Phi(y)$ for $\left(0 \leq y \leq y_{\mathrm{PE}}\right)$, relative to the equilibrium potential for reaction $j$ evaluated at reference concentrations, $U_{\mathrm{j}, \mathrm{ref}}$.

It is useful to note that for the logarithmic concentration terms in Eq. [16] the ratio $c_{1} / \rho_{o}$ is in units of $\mathrm{mol} / \mathrm{kg}$ for solute species. Also, for dissolved gases (e.g., dissolved oxygen) the reference partial pressure of the gas above the solution, $p_{\mathrm{i} \text {.ref }}$, should appear explicitly in $U_{\mathrm{j}, \mathrm{ref}}$ and the ratio of the partial pressure of the gas at the reaction site relative to a reference partial pressure should appear as a multiplier term in Eq. [14]. Here $p_{0_{2} \text {, ref }}=1 \mathrm{~atm}$ so it does not appear in Eq. [16]; and, because the multiplier term appears as a ratio it is reasonable to replace it by the dissolved gas concentration ratio [19]

$$
\frac{p_{i}}{p_{i, \text { ref }}}=\frac{c_{i}}{c_{i, \text { ref }}}
$$

Although the working electrode potential, $V$, is assumed to be constant everywhere within the solid matrix of the porous layer, the solution potential, $\Phi$, is assumed to be a function of $y$. Therefore, the current density predicted by the Butler-Volmer kinetic expression, Eq. [14], also depends on $y$.

A value for the average superficial current density, $i_{\mathrm{j}}$ (i.e., current relative to the projected planar area of the porous electrode layer), is found by integrating the local volume average current density, $a j_{j}$

$$
i_{j}=\int_{y=0}^{y=y_{\mathrm{PE}}} a j_{\mathrm{j}} d y
$$

\section{Boundary Conditions}

The bulk conditions are simply that the concentration of each species is equal to its bulk concentration at the reference electrode Luggin tip

$$
c_{\mathrm{i}}\left(y_{\mathrm{RE}}\right)=c_{\mathrm{i} . \mathrm{bulk}}
$$

and the solution potential is set at a fixed value

$$
\Phi\left(y_{\mathrm{RE}}\right)=\Phi_{\mathrm{RE}}
$$

The values used for $c_{i . b u l k}$ must of course satisfy the electroneutrality condition. At the electrode backing plate or current collector $(y=0)$, the boundary condition is that the flux of each species $i$ is zero

$$
\mathbf{N}_{1}=0
$$

This is due to the assumption that the porous layer backing is solid and no species diffuses into, is deposited on, or is dissolved away from the substrate itself. This would have to be changed for a dissolving substrate. The condition of electroneutrality is also assumed to hold at $y=0$

$$
\sum_{i} z_{i} c_{i}=0
$$

At the boundary between the two regions the electroneutrality condition holds and the flux of each species $i$ across the porous electrode-electrolyte interface is continuous

$$
\mathbf{N}_{\text {iporous region }}=\left.\mathbf{N}_{\mathrm{i}}\right|_{\text {diffusion layer }}
$$

\section{Solution Technique}

The above equations can be solved by using a finite difference method [16] to obtain concentration and potential profiles throughout the modeled region (diffusion layer and porous electrode layer). These values can then be used to determine local volume average current densities, $a j_{j}$, throughout the porous layer using the ButlerVolmer expression, Eq. [14]. These local volume average current densities can be integrated over the entire porous layer to yield a superficial current density for each reaction by applying Simpson's rule to Eq. [21]. From this result, the total current density can be found by summing the superficial current densities due to the individual reactions

$$
i_{\mathrm{T}}=\sum_{\mathrm{i}} i_{\mathrm{j}}
$$

It is worth noting that this value for $i_{\mathrm{r}}$ is equal to the value that is obtained for $i_{\mathrm{T}}$ by using Newman's expression for the total current density in an electrolytic solution (1)

$$
i_{\mathrm{T}}=\mathbf{F} \sum z_{\mathrm{i}} \mathbf{N}_{\mathrm{i}}
$$

applied at the electrode-electrolyte interface $\left(y=y_{\mathrm{PE}}\right)$. Both of these expressions (Eq. [27] and [28]) yield $i_{\mathrm{T}}=0$ during the corrosion process since no net current density exists during corrosion. In other words, at the corrosion potential the total current density equals zero, and the rate of metal oxidation is equal to the rate of oxygen reduction.

\section{Results and Discussion}

The initial corrosion rate of a porous layer on a rotating disk electrode can be predicted by using the model set forth above. The utility of this model can be demonstrated by considering the oxidation of iron accompanied by the reduction of oxygen in an aerated caustic solution

$$
\begin{gathered}
\mathrm{Fe} \rightarrow \mathrm{Fe}^{2+}+2 e^{-} \\
\mathrm{O}_{2}+2 \mathrm{H}_{2} \mathrm{O}+4 e^{-} \rightarrow 4 \mathrm{OH}^{-}
\end{gathered}
$$

This case is considered here to illustrate the dependence of the corrosion rate of iron on changes in the porous 
Table I. Fixed physical parameters

\begin{tabular}{ll} 
Parameter & \multicolumn{1}{c}{ Value } \\
\hline$T$ & $298.15 \mathrm{~K}$ \\
$\Omega$ & $377 \mathrm{~s}^{-1}(3600 \mathrm{rpm})$ \\
$\rho_{0}$ & $1 \times 10^{-3} \mathrm{~kg} / \mathrm{cm}^{3}$ \\
$\nu$ & $9.72 \times 10^{-3} \mathrm{~cm}^{2} / \mathrm{s}$ \\
$N_{\mathrm{M}, P \mathrm{E}}$ & 2.0 \\
$y_{\mathrm{RE}}$ & $0.02 \mathrm{~cm}$ \\
$U_{\mathrm{RE}}{ }^{\mathrm{a}}$ & $0.0 \mathrm{~V}$ \\
& $0.242 \mathrm{~V}$
\end{tabular}

a Saturated calomel reference electrode.

Table II. Kinetic and thermodynamic fixed parameters for a porous iron layer on a RDE

\begin{tabular}{cccccr}
\hline Reaction $j$ & $\alpha_{\mathrm{aj}}$ & $\alpha_{\mathrm{c},}$ & $n_{\mathrm{j}}$ & $j_{\text {ij.data }}\left(\mathrm{A} / \mathrm{cm}^{2}\right)$ & $U_{1}^{\theta}(\mathrm{V})$ \\
\hline 1 & 1 & 1 & 2 & $1.10 \times 10^{-6}[\operatorname{Ref.}(10)]$ & -0.440 \\
2 & 3 & 1 & 4 & $1.24 \times 10^{-24}[\operatorname{Ref} .(9)]$ & 0.401
\end{tabular}

structure (specific surface area and porous layer thickness). The results of changing the caustic concentration [16] are also presented. For consistency in nomenclature, the metal oxidation reaction (Eq. [29]) carrys a reaction index $j=1$, and the oxygen reduction reaction ( $\mathrm{Eq}$. [30]) is referred to by the index $j=2$.

\section{Behavior of Iron Porous Electrode Layer}

The fixed parameters used are given in Tables I-III. The value given in Table II for the exchange current density for oxygen reduction $\left(i_{0_{2} \text {,data }}\right)$ was obtained from Vahdat and Newman (9) by using the first equation below their Eq. [18] with $U=1.229 \mathrm{~V}$ (as given by them below their Eq. [15]), $\alpha_{c}=1.0$, and $T=298.15 \mathrm{~K}$. This value is probably too low, but it was used anyway to illustrate the capability of the model. In fact, one may want to use the model together with data and a parameter estimation technique to determine a value for $i_{0_{2}, d a t a}$. The diffusion coefficients in Table III were chosen arbitrarily. Solution concentrations were varied according to the values presented in Table IV. Reference values for concentrations were taken to be the bulk concentrations, and Eq. [15] was used to correct the exchange current densities accordingly.

Typical concentration profiles for ferrous ion and dissolved oxygen at the corrosion potential and current density are shown in Fig. 3. During corrosion, oxygen is transported from the bulk to the porous iron layer where

Table III. Component reaction orders and transport properties for a porous iron layer on a RDE

\begin{tabular}{lrrrrr}
\hline Component $i$ & $z_{1}$ & $s_{\mathrm{i} 1}$ & $s_{\mathrm{t} 2}$ & $D_{\mathrm{i}}\left(\mathrm{cm}^{2} / \mathrm{s}\right)$ & $\begin{array}{c}c_{\text {1. clata }} \\
\left(\mathrm{mol} / \mathrm{cm}^{3}\right)\end{array}$ \\
\hline $\mathrm{Na}^{+}$ & +1 & 0 & 0 & $2.084 \times 10^{-5}$ & $1.0 \times 10^{-10}$ \\
$\mathrm{OH}^{-}$ & -1 & 0 & 4 & $5.260 \times 10^{-5}$ & $1.0 \times 10^{-10}$ \\
$\mathrm{O}_{2}$ & 0 & 0 & -1 & $1.900 \times 10^{-5}$ & $1.0 \times 10^{-7}$ \\
$\mathrm{Fe}^{+2}$ & +2 & -1 & 0 & $1.500 \times 10^{-5}$ & $4.0 \times 10^{-3}$
\end{tabular}

Table IV. Parameters for $1.0,0.1$, and $0.01 \mathrm{M}$ caustic solutions for a porous iron layer on a RDE

\begin{tabular}{|c|c|c|c|}
\hline Solution & $1.0 M \mathrm{NaOH}$ & $0.1 M \mathrm{NaOH}$ & $0.01 M \mathrm{NaOH}$ \\
\hline Component $i$ & $c_{\mathrm{r}, \mathrm{ref}}\left(\mathrm{mol} / \mathrm{cm}^{3}\right)$ & $c_{1 . \mathrm{r}}\left(\mathrm{mol} / \mathrm{cm}^{3}\right)$ & $c_{1, \pi \mathrm{r}}\left(\mathrm{mol} / \mathrm{cm}^{3}\right)$ \\
\hline $\begin{array}{l}\mathrm{Na}^{+} \\
\mathrm{OH}^{-} \\
\mathrm{O}_{2}[\mathrm{Ref} .(30)] \\
\mathrm{Fe}^{+2}\end{array}$ & $\begin{array}{ll}0.99998 \times 10^{-3} \\
1.00 & \times 10^{-3} \\
0.96 & \times 10^{-63} \\
1.00 & \times 10^{-8}\end{array}$ & $\begin{array}{l}0.9998 \times 10^{-4} \\
1.00 \times 10^{-4} \\
1.34 \times 10^{-6} \\
1.00 \times 10^{-k}\end{array}$ & $\begin{array}{l}0.998 \times 10^{-5} \\
1.00 \times 10^{-5} \\
1.39 \times 10^{-4} \\
1.00 \times 10^{-4}\end{array}$ \\
\hline $\begin{array}{l}U_{1, \text { wer }}(\mathrm{V}) \\
U_{2, \mathrm{ter}}(\mathrm{V})\end{array}$ & $\begin{array}{r}-0.8299 \\
0.1590\end{array}$ & $\begin{array}{r}-0.8299 \\
0.2182\end{array}$ & $\begin{array}{r}-0.8299 \\
0.2773\end{array}$ \\
\hline $\begin{array}{l}i_{(1, \mathrm{rut}}\left(\mathrm{A} / \mathrm{cm}^{2}\right) \\
i_{i 2, \mathrm{r}, \mathrm{f}}\left(\mathrm{A} / \mathrm{cm}^{2}\right)\end{array}$ & $\begin{array}{l}1.739 \times 10^{-18} \\
6.736 \\
\times 10^{-17}\end{array}$ & $\begin{array}{l}1.739 \times 10^{-9} \\
8.680 \times 10^{-1 k}\end{array}$ & $\begin{array}{l}1.739 \times 10^{-9} \\
8.904 \times 10^{-14}\end{array}$ \\
\hline
\end{tabular}

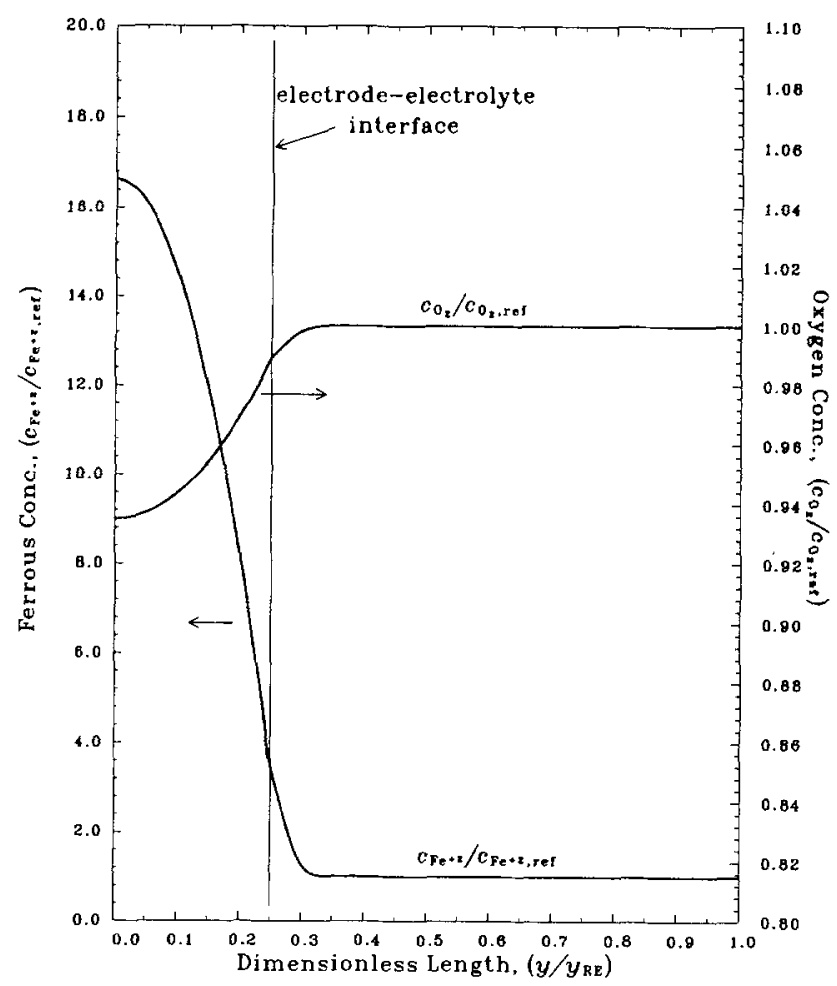

Fig. 3. Concentration profiles of the major reactants at the corrosion potential for a porous iron layer on a RDE in $1.0 \mathrm{M} \mathrm{NaOH}$ where $a=$ $200 \mathrm{~cm}^{-1}, \delta_{\mathrm{PE}}=0.005 \mathrm{~cm}, Y_{\mathrm{RE}}=0.02 \mathrm{~cm}$, and $\left(V-\Phi_{\mathrm{RE}}\right)=0.555 \mathrm{~V}$.

it diffuses to reactive sites within the porous layer. Ferrous ions are transported through the electrode away from reactive sites as they are formed. At the porous electrode-electrolyte interface a change is seen in the slope of both the oxygen and ferrous concentration curves. These changes in slope are due to the boundary condition given by Eq. [26] which sets the flux of each species on the electrolyte side of the boundary equal to the flux of that species within the porous layer. Since the diffusion coefficient of a species within the porous layer

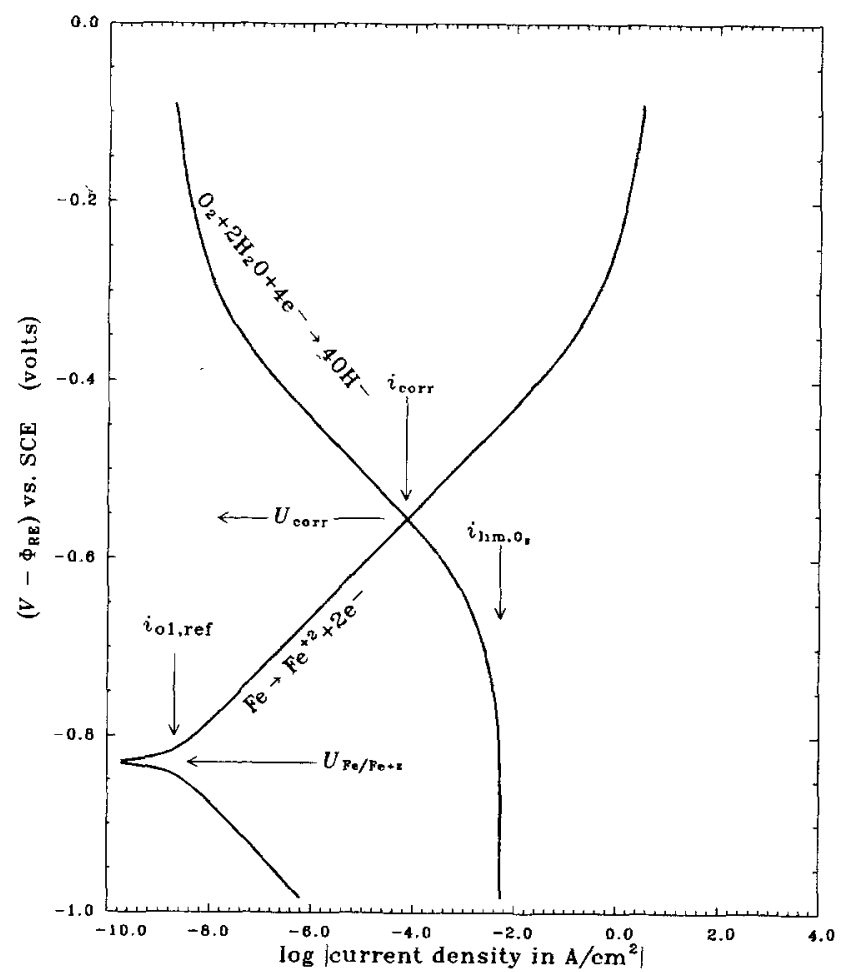

Fig. 4. Behavior of a porous iron layer on a rotating disk electrode in $1.0 \mathrm{M}$ caustic at a rotation speed of $3600 \mathrm{rpm}$ and a specific area, $a=$ $200 \mathrm{~cm}^{-1}$ where $\delta_{\mathrm{PF}}=0.005 \mathrm{~cm}$. 
is smaller than its bulk value (see Eq. [11]), the concentration gradient of a species must be larger in the porous layer to compensate for its smaller diffusion coefficient there. The flat appearance of the concentration profiles at the electrode backing plate is due to the boundary condition at $y=0$ that states that the flux of species $i$ is equal to zero at that point.

Figure 4 shows a typical predicted current-potential plot. Recall that the model is of the potentiostatic type so that the potential driving force, $V-\Phi_{\mathrm{RE}}$, represents the difference between the potential of the working electrode, $V$, and the solution potential at the reference electrode, $\Phi_{\mathrm{RE}}$. This quantity is the potential which would be measured or set in an experimental cell. The current density values shown in Fig. 4 were determined according to Eq. [14] and [21]. At the corrosion potential, $U_{\text {curr }}=(V-$ $\left.\Phi_{\mathrm{RE}}\right)_{\mathrm{corr}}$, the total current density is zero (i.e., the rate of iron oxidation is equal to the rate of oxygen reduction) and corrosion occurs. This can be seen in Fig. 4 where the individual reaction current density curves intersect. At this point the corrosion current density, $i_{\text {corr }}$, is equal to the iron current density, $i_{1}$, and the negative of the oxygen reduction current density, $i_{2}$, according to the relationship

$$
i_{\mathrm{curr}}=i_{1}=-i_{2}
$$

and

$$
i_{\mathrm{T}}=0=i_{1}+i_{2}
$$

According to Eq. [32], the sum of the reaction current densities gives the total current density which would be that current density measured in an experimental cell.

At the iron reaction equilibrium, $U_{\mathrm{Fe} / \mathrm{Fe}+2}$ (shown in Fig. 4 and equal to $U_{1, \text { ref }}$ ) the forward rate of iron oxidation is equal to the reverse rate of iron reduction and is given by the exchange current density, $i_{01, \text { ref }}$. This implies that the iron reaction is in equilibrium at this potential. As the potential ( $V-\Phi_{\mathrm{RE}}$ ) is increased cathodically (i.e., negative direction) beyond the iron reaction equilibrium potential the reaction will begin to occur in reverse and electrodeposition of iron will occur. Oxygen continues to be reduced in this region but reacts at a constant rate which is limited by the diffusion of oxygen from the bulk to the electrode porous layer, $i_{1 \mathrm{im}, 0_{2}}$. Similarly, as the potential is increased anodically (i.e., positive direction)

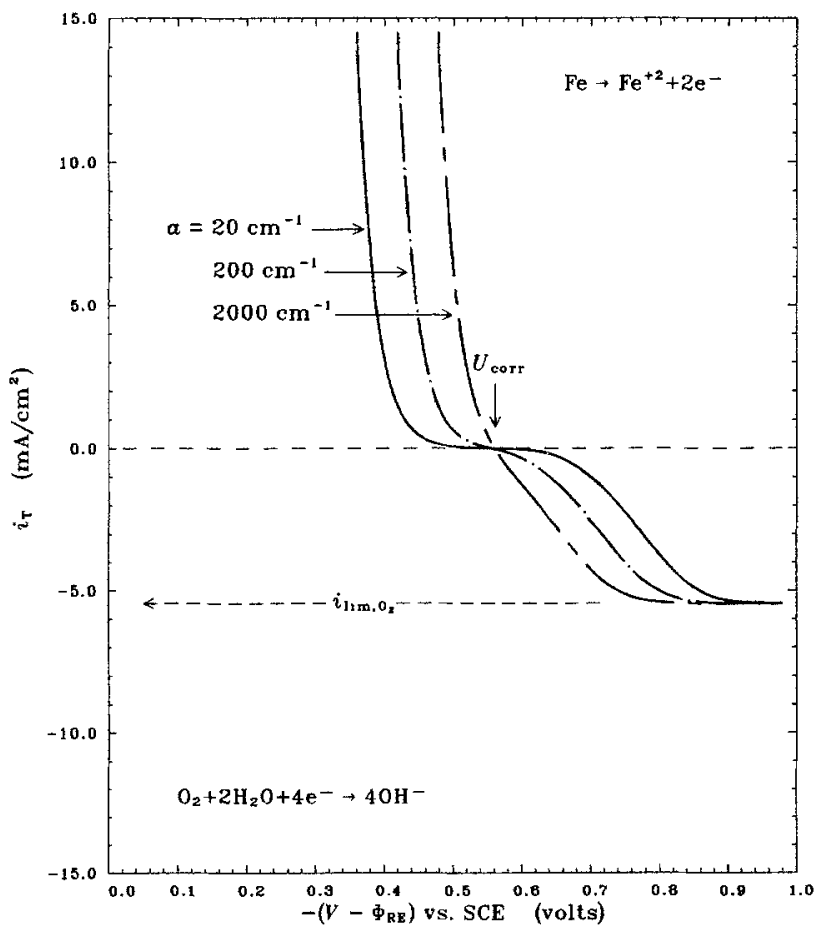

Fig. 5. Current-potential behavior of an iron RDE with an iron porous layer on it. The electrolyte is $1.0 \mathrm{M} \mathrm{NaOH}$ and the rotation speed is $3600 \mathrm{rpm}$ where $\delta_{\mathrm{PE}}=0.005 \mathrm{~cm}$.
Table $V$. Corrosion results for an iron porous electrode of various porous compositions in $1.0,0.1$, and $0.01 \mathrm{M}$ caustic solutions

\begin{tabular}{crlll}
\hline$c_{\mathrm{OH}^{-} . \mathrm{ret}}\left(\mathrm{mol} / \mathrm{cm}^{3}\right)$ & $a\left(\mathrm{~cm}^{-1}\right)$ & $\delta_{\mathrm{rE}}(\mathrm{cm})$ & $U_{\text {curr }}(\mathrm{V})$ & \multicolumn{1}{c}{$\begin{array}{l}i_{\text {corr }} \\
\left(\mathrm{mA} / \mathrm{cm}^{3}\right)\end{array}$} \\
\hline \multirow{2}{*}{$1.0 \times 10^{-3}$} & 20 & 0.005 & 0.555 & 0.00779 \\
& 200 & 0.005 & 0.555 & 0.0763 \\
& 2000 & 0.005 & 0.558 & 0.624 \\
& 200 & 0.0005 & 0.555 & 0.00779 \\
& 200 & 0.001 & 0.555 & 0.0156 \\
& 200 & 0.01 & 0.557 & 0.144 \\
\hline $1.0 \times 10^{-4}$ & 20 & 0.005 & 0.552 & 0.00885 \\
& 200 & 0.005 & 0.552 & 0.0870 \\
& 2000 & 0.005 & 0.556 & 0.737 \\
\hline $1.0 \times 10^{-5}$ & 20 & 0.005 & 0.551 & 0.00897 \\
& 200 & 0.005 & 0.551 & 0.0881 \\
& 2000 & 0.005 & 0.554 & 0.747
\end{tabular}

from the corrosion potential, iron will dissolve but the oxygen reaction will begin to occur in reverse where hydroxide ion will oxidize to oxygen beyond the oxygen reaction equilibrium potential (not shown in Fig. 4). The departure from linearity for the curves in the top part of Fig. 4 is due to ohmic drop (16).

Figure 5 shows a comparison of the predicted currentpotential curves for porous electrodes of varying a specific surface areas in $1.0 \mathrm{M} \mathrm{NaOH}$. Holding the porous layer thickness constant at $0.005 \mathrm{~cm}$ as the specific area is increased causes a noticeable increase in the magnitude of the total current density and also the corrosion current density as seen in the first three entries for each caustic solution concentration in Table $V$. This seems reasonable because a larger electrode surface area is available for reaction, and the solubility of oxygen increases with decreasing $\mathrm{NaOH}$ concentration (17).

A similar effect is shown in Fig. 6 for the porous layer thickness $\delta_{\mathrm{PE}}$. Holding the specific area constant at 200 $\mathrm{cm}^{-1}$ as the porous layer thickness is increased causes a noticeable increase in the magnitude of the total current density and also the corrosion current density as shown in the last three entries for the $1.0 \mathrm{M}$ caustic solution in Table $\mathrm{V}$. However, note that over the range of values presented, changing the porous layer thickness does not

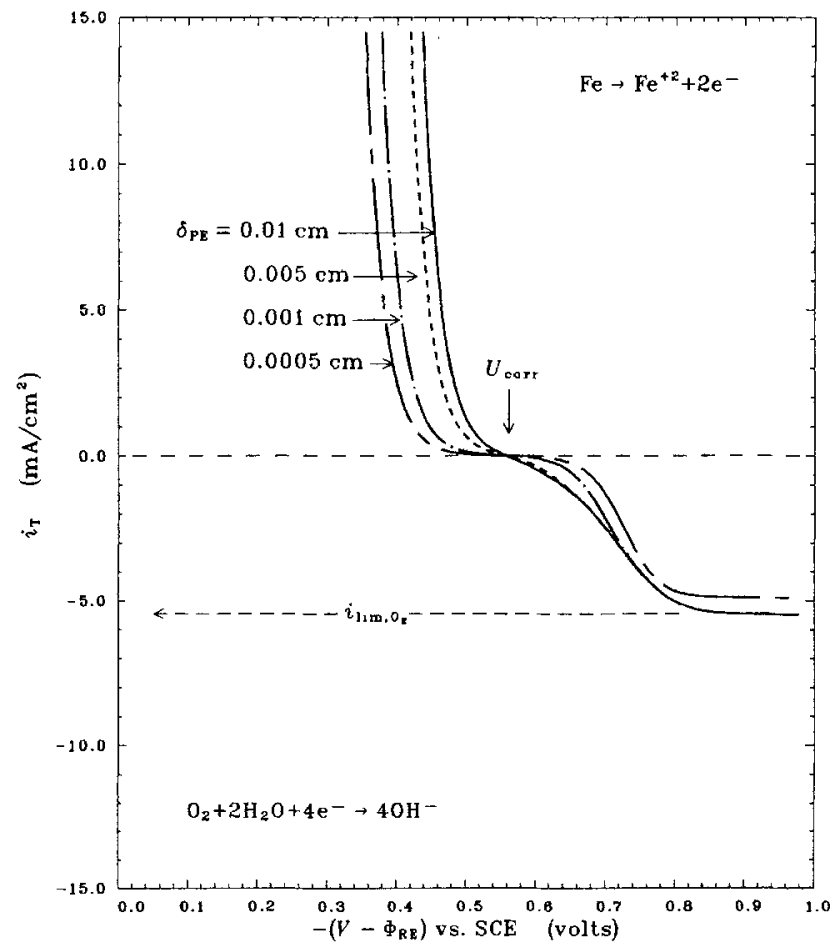

Fig. 6. Effect of an iron porous layer thickness on a RDE. The electrolyte is $1.0 \mathrm{M} \mathrm{NaOH}$ and the rotation speed is $3600 \mathrm{rpm}$ where $a=200$ $\mathrm{cm}^{-1}$. 
have a noticeable effect on the corrosion potential (Table $\mathrm{V})$, but for a very thin porous layer $(0.0005 \mathrm{~cm})$ the limiting current density decreases (Fig. 6).

Table V summarizes the results for the iron corrosion study. For larger reactive surface areas as defined by larger specific surface area, $a$, and increased porous layer thickness, $\delta_{\mathrm{PE}}$, higher rates of corrosion are seen in each concentration range. The corrosion potential appears to be essentially constant in the concentration ranges studied. The effect of caustic concentration on corrosion rate of an iron porous electrode also appears to be negligible.

\section{Conclusions}

The model presented here could be used to determine many of the physical features of interest when using porous electrode layers. In particular, the thickness of a porous layer on a RDE could be found by using the model and parameter estimation. This may be desirable because it is difficult to measure the thickness of a porous layer on a RDE. This thickness could be used to predict the approximate lifetime of the porous layer by assuming that the predicted initial corrosion rate would be constant over the lifetime of the layer. This may be particularly useful in industrial applications where the lifetime of a porous layer may be an important design consideration.

\section{Acknowledgment}

The authors are grateful for the support of this work in part by The Dow Chemical Company.

Manuscript submitted July 25, 1986; revised manuscript received Feb. 26, 1987.

The Dow Chemical Company assisted in meeting the publication costs of this article.

\section{LIST OF SYMBOLS}

\section{$a^{\prime} \quad 0.51023$}

a electroactive specific surface area of the porous layer, $\mathrm{cm}^{-1}$

$a j_{\mathrm{i}} \quad$ local volume average current density, $\mathrm{A} / \mathrm{cm}^{3}$

$c_{1} \quad$ concentration of species $i, \mathrm{~mol} / \mathrm{cm}^{3}$

$c_{\text {i.bulk }}$ bulk solution concentration of species $i, \mathrm{~mol} / \mathrm{cm}^{3}$

$c_{\text {idata }}$ data solution concentration of species $i, \mathrm{~mol} / \mathrm{cm}^{3}$

$c_{i, \text { ref }}$ reference concentration of species $i, \mathrm{~mol} / \mathrm{cm}^{3}$

$c_{\mathrm{i} . \mathrm{RE}} \quad$ concentration of species $i$ for reference electrode reaction, $\mathrm{mol} / \mathrm{cm}^{3}$

$D_{\mathrm{i}} \quad$ diffusion coefficient of species $i, \mathrm{~cm}^{2} / \mathrm{s}$

$D_{l, \mathrm{e}} \quad$ effective diffusion coefficient of species $i$ in a porous layer, $\mathrm{cm}^{2} / \mathrm{s}$

F Faraday's constant, $96,487 \mathrm{C} / \mathrm{mol}$

$i_{\text {lim. } 0_{2}}$ limiting current density for oxygen reduction, $\mathrm{A} / \mathrm{cm}^{2}$

$i_{\text {corr }} \quad$ corrosion current density, $\mathrm{A} / \mathrm{cm}^{2}$

$i_{\mathrm{j}} \quad$ average superficial current density due to reaction $j, \mathrm{~A} / \mathrm{cm}^{2}$

$i_{\mathrm{oj}, 0} \quad$ exchange current density at surface concentrations for reaction $j, \mathrm{~A} / \mathrm{cm}^{2}$

$i_{\text {oj,data }}$ exchange current density at data concentrations for reaction $j, \mathrm{~A} / \mathrm{cm}^{2}$

$i_{\text {oj,ref }}$ exchange current density at reference concentrations for reaction $j, \mathrm{~A} / \mathrm{cm}^{2}$

$i_{\mathrm{T}} \quad$ total current density, $\mathrm{A} / \mathrm{cm}^{2}$

$j_{\mathrm{j}} \quad$ local current density due to reaction $j, \mathrm{~A} / \mathrm{cm}^{2}$

$n_{j} \quad$ number of electrons transferred in reaction $j$

$n_{\mathrm{RE}} \quad$ number of electrons transferred in reference electrode reaction

$\mathbf{N}_{\mathrm{i}} \quad$ flux vector of species $i, \mathrm{~mol} / \mathrm{cm}^{2} \cdot \mathrm{s}$

$N_{\text {M.PE }} \quad$ MacMullin number for the porous electrode layer $(=\tau / \epsilon)$ $p_{i} \quad$ partial pressure of species $i$ at liquid-vapor interface, atm

$p_{i j} \quad$ anodic reaction order of species $i$ in reaction $j$

$q_{1 j} \quad$ cathodic reaction order of species $i$ in reaction $j$

$q_{R} \quad$ universal gas constant, $8.3143 \mathrm{~J} / \mathrm{mol} \cdot \mathrm{K}$

$R_{\mathbf{i}} \quad$ homogeneous reaction rate of species $i, \mathrm{~mol} /$ $\mathrm{cm}^{3} \cdot \mathrm{s}$

$R^{\prime} \quad$ pseudohomogeneous reaction rate of species $i$ due to electrochemical reactions within the porous electrode layer, $\mathrm{mol} / \mathrm{cm}^{3} \cdot \mathrm{s}$

$s_{\mathrm{ij}} \quad$ stoichiometric coefficient of species $i$ in reaction $j$

$t$ time, $s$

$T$ absolute temperature, $K$

$u_{\mathrm{i}} \quad$ mobility of species $i, \mathrm{~mol} \cdot \mathrm{cm}^{2} / \mathrm{J} \cdot \mathrm{s}$

$U_{\text {corr }}$ corrosion potential, $V$

$U_{\mathbf{j}, \text { ref }}$ equilibrium potential for reaction $j$ at the reference concentrations of species $i, \mathrm{~V}$

$U_{\mathrm{i}}{ }^{*} \quad$ standard electrode potential for reaction $j, \mathrm{~V}$

$U_{\mathrm{RE}}{ }^{\theta} \quad$ standard electrode potential for reference electrode reaction, $\mathrm{V}$

$U_{\mathrm{RE}} \quad$ reference electrode potential at reference concentrations, $\mathrm{V}$

v electrolyte velocity vector, $\mathrm{cm} / \mathrm{s}$

$v_{y} \quad$ electrolyte velocity in the normal direction, $\mathrm{cm} / \mathrm{s}$

$V \quad$ potential of the porous electrode, $\mathrm{V}$

$y$ normal coordinate, $\mathrm{cm}$

$y_{\mathrm{PE}}$ position of porous electrode-electrolyte interface, $\mathrm{cm}$

$y_{\mathrm{RE}} \quad$ position of reference electrode, $\mathrm{cm}$

$z_{\mathrm{i}} \quad$ charge number of species $i$

Greek Symbols

$\boldsymbol{\alpha}_{\mathrm{aj}} \quad$ anodic transfer coefficient for reaction $j$

$\alpha_{c j} \quad$ cathodic transfer coefficient for reaction $j$

$\gamma_{i j}$ exponent in the composition dependence of the exchange current density

$\delta_{\mathrm{PE}} \quad$ porous electrode layer thickness, $\mathrm{cm}$

$\epsilon$ porosity or void volume fraction

$\epsilon c_{i} \quad$ superficial concentration of species $i$ in a porous layer, $\mathrm{mol} / \mathrm{cm}^{3}$

$v \quad$ kinematic viscosity, $\mathrm{cm}^{2} / \mathrm{s}$

$\rho_{0} \quad$ pure solvent density, $\mathrm{kg} / \mathrm{cm}^{3}$

$\tau \quad$ tortuosity of porous material

$\Phi$ potential in solution, $\mathrm{V}$

$\Phi_{\mathrm{RE}} \quad$ potential in bulk solution, at $y_{\mathrm{RE}}, \mathrm{V}$

$\Omega$ disk rotation velocity, $\mathrm{rad} / \mathrm{s}$

\section{REFERENCES}

1. J. Newman and W. Tiedemann, AIChE J., 21, 1 (1975).

2. O. S. Ksenzhek, Zh. Fiz. Khim., 36, 243 (1962).

3. I. G. Gurevich and V. S. Bagotzky, Electrochim. Acta, 9, 1151 (1964).

4. J. Van Zee and R. E. White, This Journal, 130, 2003 (1983).

5. E. A. Grens and C. W. Tobias, Electrochim. Acta, 10, 761 (1965).

6. E. A. Grens, ibid., 15, 1047 (1970).

7. L. G. Austin, ibid., 14, 639 (1969).

8. Y.C. Chang and G. Prentice, Electrochim. Acta, 31, 579 (1986).

9. N. Vahdat and J. Newman, This Journal, 120, 1682 (1973).

10. C. G. Law and J. Newman, ibid., 126, 2150 (1979).

11. C. G. Law and J. Newman, ibid., 133, 37 (1986).

12. J. S. Dunning, Ph.D. Thesis, University of California, Los Angeles, CA (1971).

13. J. A. Trainham, Ph.D. Thesis, University of California, Berkeley, CA (1979).

14. T. I. Evans and R. E. White, This Journal, 134, 866 (1987).

15. R. E. White, S. E. Lorimer, and R. Darby, ibid., 130, 1123 (1983).

16. W. E. Ryan, M.S. Thesis, Texas A \&M University, College Station, TX (1986)

17. A. Yasunishi, Kagaku Kogaku Rombunshu, 4, 185 (1978). 